\title{
Sistem Otomatisasi Desalinasi Air Laut Berbasis Internet of Things
}

\section{( Automation System Based Internet Of Things For Sea Water Desalination )}

\author{
Deni Maulana Ihsan ${ }^{1 *}$, Novi Prihatiningrum², Limawati Handayani ${ }^{3}$, Faisal \\ Budiman $^{4 *}$ \\ 1,2,4 Teknik Elektro, Universitas Telkom \\ E-mail:denimaul@telkomuniversity.ac.id,,nprihatiningrum@telkomuniversity.ac.id, \\ faisalbudiman@telkomuniversity.ac.id (Corresponding Author) \\ ${ }^{3}$ Prodi Teknik Manajemen Industri Pertahanan, Akademi Angkatan Udara \\ E-mail:watielimo@aau.ac.id
}

\begin{abstract}
The design of automatic sea water desalination device based on Internet of Things (IoT) utilizing the thermal desalination method has been carried out. Thermal desalination is a process of salt water into pure water vapor conversion, thus the salt, minerals, and other contaminants that present in the water will be separated. The system is useful to convert sea water into fresh water, which is beneficial for community that living at coast area. The designed thermal desalination device consists of temperature, salinity, and ultrasonic sensors, which are connected to a microcontroller. In addition, the device is also equipped with an IoT system and a mobile application, for controlling and monitoring features through an android application. When the application in operation, the temperature, volume, and salinity levels data are sent via the IoT platform, so that it can be monitored by the users through an android application in mobile phone. The experimental results showed that this desalination device has succeeded in converting salt water into freshwater, with a percentage of freshwater volume after desalination process reaching 92.74\%. For each process, the duration requires about $3 h$. The design results, testing, mechanism, and discussion in more detail are presented in this article.
\end{abstract}

Keywords-Desalination, Internet of Things, Salinity

Abstrak- Perancangan sistem otomatis desalinasi air laut berbasis Internet of Things (IoT) memanfaatkan metode desalinasi termal telah dilakukan. Desalinasi termal merupakan proses perubahan air garam menjadi uap air, sehingga uap air ini bebas dari garam, mineral, dan kontaminasi lainnya yang ada dalam air laut, sehingga dapat digunakan untuk mengubah air laut menjadi air tawar, dan bermanfaat bagi masyarakat yang tinggal di daerah pesisir. Alat desalinasi termal yang dibuat terdiri dari sensor suhu, salinitas dan ultrasonik, yang terhubung dengan suatu mikrokontroller. Selain itu, alat juga dilengkapi dengan sistem IoT dan sebuah mobile application yang memiliki fitur kontrol dan pemantauan melalui aplikasi android. Saat alat beroperasi data suhu, volume, dan kadar salinitas dikirimkan melalui platform IoT sehingga dapat dipantau oleh pengguna menggunakan aplikasi android. Hasil pengujian menunjukkan alat desalinasi ini berhasil mengubah air garam menjadi air tawar, dengan persentase volume air tawar setelah desalinasi sebesar 92,74\% dengan durasi 3 jam untuk setiap prosesnya. Hasil perancangan, pengujian dan diskusi yang lebih detail disajikan dalam artikel ini.

Kata Kunci-Desalinasi, Internet of Things, salinitas

*Penulis Korespondensi (Deni Maulana Ihsan)

E-mail:denimaul@telkomuniversity.ac.id 


\section{Pendahuluan}

$\mathrm{K}_{\mathrm{K}}^{\mathrm{e}}$ ekurangan air tawar atau air bersih sering terjadi di daerah pesisir pantai, sebagai contoh di Kecamatan Selat Nasik [1] dan pesisir utara Lamongan [2]. Berdasarkan data dari Bank Dunia dan Perserikatan Bangsa-Bangsa, ada sekitar 2,5 miliar orang (36\% dari populasi dunia) yang tinggal di daerah kekurangan air [3]. Kurangnya ketersediaan air bersih di akan mengakibatkan terkendalanya aktivitas sehari-hari, mengingat air adalah kebutuhan paling utama dalam kehidupan. Pada dasarnya, sumber air yang berpotensi untuk dimanfaatkan di daerah pesisir dapat berasal dari air laut, ataupun berasal dari air tanah. Namun, untuk air tanah terkadang hanya berada pada titik tertentu dan tidak sama untuk tiap daerah. Air laut sangat berlimpah dan sangat berpotensi untuk dijadikan sumber air tawar, tetapi perlu melalui proses tertentu dan mungkin kompleks secara proses. Dibutuhkan suatu proses yang sistem yang dapat memproduksi air tawar dari air laut yang efektif dan mudah, dengan harapan dapat memenuhi kebutuhan air tawar, khususnya di daerah pesisir laut.

Pada daerah pesisir, terdapat beberapa metode untuk mendapatkan air tawar, di antaranya melalui pembuatan sumur bor, desalinasi membran, dan desalinasi termal. Sumur bor merupakan metode membuat sumur dengan kedalaman lebih dari $50 \mathrm{~m}$, tetapi terkadang air yang didapat masih keruh dan terasa agak asin [4]. Metode lain adalah menggunakan desalinasi membran, yakni pemisahan zat terlarut dengan memanfaatkan perbedaan tekanan [5]. Dalam hal ini, garam pada air laut sebagai zat terlarut dan air adalah pelarutnya. Metode desalinasi membran ini efektif untuk digunakan, namum prosesnya kompleks dan biaya operasional dan perawatannya tinggi. Selain itu, ada satu metode yang dinamakan desalinasi termal, merupakan proses memisahkan garam terlarut untuk mendapatkan air dengan memanfaatkan titik didih air yang lebih rendah daripada garam air lau [6]. Metode desalinasi termal tergolong efektif karena memiliki keuntungan proses yang simpel, perawatan mudah, dan biaya operasional yang murah. Metode ini adalah dapat dikatakan salah satu solusi terbaik untuk mengatasi kekurangan air bersih di daerah pesisir. Pada perkembangannya, metoda ini masih dilakukan secara manual dan terkadang masih terdapat defisiensi pada alat yang telah dirancang.

Pada penelitian ini, sistem otomatis desalinasi air laut berbasis Internet of Things (IoT) telah dirancang memanfaatkan metode desalinasi termal. Sistem terdiri dari sensor suhu, salinitas, ultrasonik, yang terhubung dengan mikrokontroller ESP32. Selain itu, sistem yang dirancang juga dilengkapi dengan IoT, yakni memanfaatkan koneksi Wi-Fi dan Antares, dan dilengkapi dengan sebuah mobile application, sehingga dapat dilakukan monitoring dan kendali dari jarak jauh secara real-time. Diharapkan dari sistem yang dirancang dapat membantu masyarakat daerah pesisir dalam memperoleh air tawar untuk memenuhi kebutuhannya.

\section{LANDASAN TEORI}

\section{A. Desalinasi Termal}

Desalinasi termal adalah proses memisahkan zat terlarut dari pelarutnya, dengan memanfaatkan perbedaan titik didihnya [7]. Pada umumnya, proses ini digunakan untuk memisahkan senyawa-senyawa yang berada dalam satu fasa, yakni fasa cair-cair. Senyawasenyawa yang terdapat dalam campuran akan menguap pada saat mencapai titik didih masingmasing. Dalam hal proses mengubah air laut menjadi air tawar, proses ini memanfaatkan titik didih air yang lebih rendah daripada garam air laut. Titik didih air diketahui adalah $100{ }^{\circ} \mathrm{C}$ sedangkan garam masih jauh di atasnya. Ketika air laut mengalami pemanasan, air tersebut akan menguap dan akan menyisakan garam yang akan mengkristal padat. Hasil penguapan air tersebut selanjutnya didinginkan kembali agar fasa air menjadi cair kembali. Hasil proses pendinginan ini menjadikan air laut tersebut air tawar. 


\section{B. Literature Review}

Berbagai penelitian telah dilakukan terkait sistem desalinasi air laut. Sebagai contoh, penelitian yang dilakukan oleh Ulvi Pri Astuti [8] melakukan perancangan sistem desalinasi termal dengan memanfaatkan panas matahari. Sistem yang dibuat menggunakan sensor switch level untuk mengatur air yang mengalir ke dalam alat desalinasi dan volume air tawar yang dapat dihasilkan sebesar 89,74 L, dengan waktu proses selama 7 jam pada intensitas matahari 485 $\mathrm{W} / \mathrm{m}^{2}$. Penelitian lain I. G. Y. Dewantara dkk. [9] berkonsentrasi pada kemampuan alat desalinasi tipe solar still dalam menyerap energi kalor matahari dengan sensor suhu dan TDS untuk memantau alat desalinasi dan alat ini memiliki efisiensi aktual maksimum $14,33 \%$. Penelitian lain yang dilakukan oleh M. A. Aziz dan N. Fajaryati [10], mereka berfokus pada percepatan proses pemanasan air laut dengan matahari menggunakan pemanas, sensor suhu digunakan untuk menjaga suhu pemanas pada $100{ }^{\circ} \mathrm{C}$ dan sensor TDS untuk mengukur kadar salinitas air hasil desalinasi, sehingga dapat mempercepat waktu hingga 55\% dari alat desalinasi sebelumnya yaitu desalinasi secara manual tanpa menggunakan element heater yang dikontrol suhunya dengan air tawar yang dihasilkan sebanyak $30 \mathrm{ml}$ dari $3000 \mathrm{ml}$ air laut. Dan lagi, penelitian yang dilakukan Akbar Sujiwa dan Atmiasri [11] memanfaatkan panel surya untuk mennyalakan pemanas yang dijaga pada suhu $100{ }^{\circ} \mathrm{C}$ yang kemudian dikembangkan oleh Akbar Sujiwa dan Sagita Rochman [12], dengan penambahan sistem kontrol dan monitoring memanfaatkan jaringan WLAN dengan akurasi pembacaan volume dan suhu perangkat berturut-turut berada pada 96,2\% dan 98,05\% untuk pengukuran suhu air. Berdasarkan hasil penelitian-penelitian di atas, sistem-sistem yang telah dirancang terkadang masih terdapat defisiensi, baik dalam sistem otomatisnya, ataupun sistem lainnya.

\section{Kadar Salinitas Air}

Kadar keasinan suatu air biasanya diukur dalam kadar salinitasnya. Salinitas didefinisikan sebagai massa (dalam satuan gr) dari semua zat padat yang terlarut dalam 1 kilogram air. Nilai salinitas bisanya dinyatakan dalam satuan $\mathrm{g} / \mathrm{kg}$, atau dapat ditulis menjadi bentuk \%o atau partper-thousand (ppt) [13]. Pada umumnya, kadar salinitas suatu air dapat diukur menggunakan Total Dissolve Solid (TDS) meter, dimana pengukurannya mengacu pada jumlah zat yang terlarut dalam suatu larutan. Prinsip kerja dari TDS meter ini berdasarkan daya hantar listrik suatu zat pada larutan yang biasanya berupa garam, mineral, logam, kalsium, dan senyawa lain yang bersifat organik dan anorganik [14]. Berdasarkan kadar salinitasnya, air dapat dikategorikan menjadi 5 jenis [15], seperti yang ditunjukkan pada Tabel I. Air yang mengandung konsentrasi salinitas TDS di bawah $1000 \mathrm{mg} / \mathrm{L}$ biasanya dapat diterima untuk konsumsi air minum [15].

TABEL I

KUALITAS AIR BERSIH

\begin{tabular}{|c|c|c|}
\hline \hline No & Kualitas & TDS $(\mathrm{mg} / \mathrm{L})$ \\
\hline 1 & Sangat Baik & $<300$ \\
\hline 2 & Baik & $300-600$ \\
\hline 3 & Cukup & $600-900$ \\
\hline 4 & Kurang & $900-1200$ \\
\hline 5 & Tidak Diterima & $>1200$ \\
\hline \hline
\end{tabular}

\section{MODEL YANG DiUSULKAN}

\section{A. Diagram Blok}

Gambar 1 (a) adalah wiring diagram dari sistem desalinasi yang dirancang. Sistem terdiri dari sensor suhu, sensor TDS, sensor ultrasonik, sensor level yang terhubung dengan mikrokontroller ESP32. Diagram blok pada Gambar 1 (b) merupakan alur kerja sistem otomatisasi desalinasi air 
laut berbasis IoT yang telah dirancang. Sistem ini terbagi menjadi dua proses, sistem desalinasi itu sendiri dan proses monitoring. Pada proses pertama, aplikasi android akan mengirimkan perintah untuk menyalakan atau mematikan prototipe melalui platform IoT Antares. ESP32 menerima perintah dari aplikasi dan mengambil data suhu, kadar salinitas, dan volume air desalinasi dari sensor-sensor. ESP32 selanjutnya memberi perintah pada relay agar pada posisi menyala dan menampilkan data monitoring di LCD. Di sisi lain, proses kedua merupakan proses pengambilan data monitoring. Pada proses ini ESP32 mengambil data suhu, kadar salinitas, dan volume air desalinasi. Data tersebut kemudian dikirimkan melalui platform IoT ke aplikasi, pengguna dapat memantau prototipe desalinasi yang didapat melalui aplikasi.
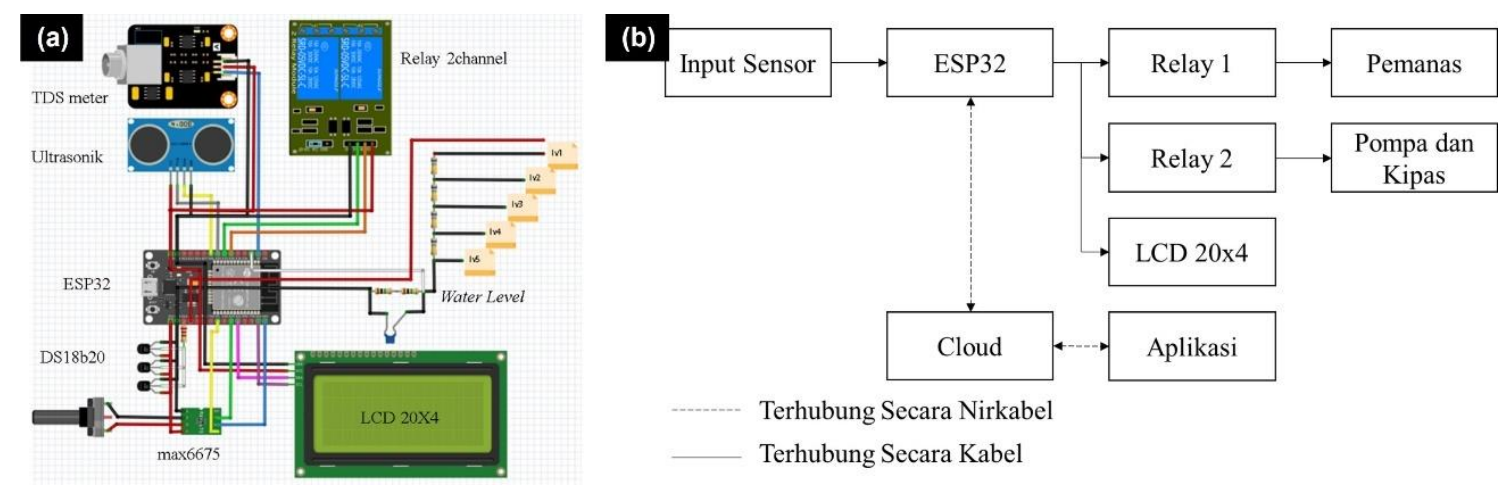

Gambar 1. (a) Wiring Diagram (b) Diagram Blok Sistem Desalinas

\section{B. Desain Alat dan Aplikasi}
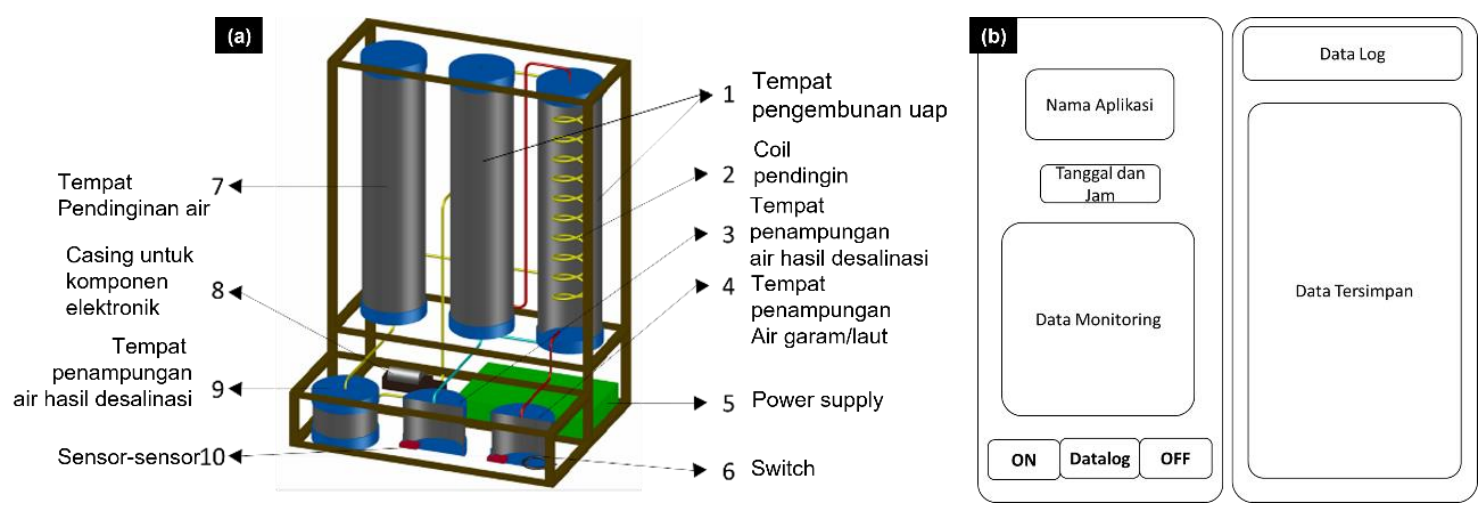

Gambar 2. (a) Desain Alat dan (b) Aplikasi

Gambar 2(a) merupakan desain perangkat keras dari sistem desalinasi yang dirancang (masing-masing bagian diindeks dengan nomor). Sistem terdiri dari dua buah kondensator sebagai tempat pengembunan uap air (indeks 1), pendingin air untuk mendinginkan air pendingin (indeks 7), penampungan air pendingin (indeks 9), penampungan air desalinasi (indeks 3), penampungan air laut atau larutan garam (indeks 4), tempat penempatan kontroler, dan power supply (indeks 5). Desain mobile applications yang ditunjukkan pada Gambar 2(b) menampilkan bahwa aplikasi terdiri dari nama aplikasi, tanggal, waktu, data monitoring, dan tombol kontrol. Sedangkan untuk layar data log menampilkan data yang tersimpan.

\section{Flowchart}

Gambar 3(a) menjelaskan flowchart program sistem otomatisasi desalinasi air laut. Pertama, proses dimulai dengan mengambil data dari Antares. Jika kontrol mendapat nilai " 0 ", maka LCD akan menampilkan layar "STOP”, sehingga program selesai dan ketika mendapat nilai "1", maka 
LCD menampilkan "START". Setelah mendapatkan nilai control, ESP32 mengambil data suhu, water level, TDS, dan volume air hasil proses desalinasi. Jika level air sama dengan "0", maka program akan memberi perintah untuk mematikan pemanas, kipas, dan pompa. Namun, ketika level air " $>0$ ", maka program memberi perintah untuk menyalakan pemanas, kipas, dan pompa. Setelah itu, jika suhu pemanas menunjukkan angka lebih dari $120^{\circ} \mathrm{C}$, maka pemanas akan dimatikan dan begitu juga sebaliknya. Terakhir, program menampilkan data sensor di LCD dan mengirimkan data tersebut ke platform IoT Antares.

Gambar 3(b) menunjukkan flowchart program aplikasi android desalinasi air laut. Program aplikasi dimulai dengan mengambil data dari Antares, kemudian ditampilkan pada UI aplikasi. Terdapat 4 (empat) kondisi pada aplikasi: Pertama, ketika tampilan utama aplikasi di swipe ke bawah, maka aplikasi mengambil data terakhir yang terdapat pada platform IoT Antares. Kedua, ketika tombol ON ditekan, maka aplikasi mengirimkan kontrol "1" ke platform IoT Antares. Ketiga, ketika tombol OFF ditekan, maka aplikasi mengirimkan kontrol "0", mengambil, dan menyimpan data monitoring terakhir dari platform IoT Antares. Keempat, ketika tombol datalog ditekan, maka tampilan utama berpindah ke tampilan datalog dan menampilkan data hasil desalinasi berupa kadar salinitas dan volume air hasil desalinasi.
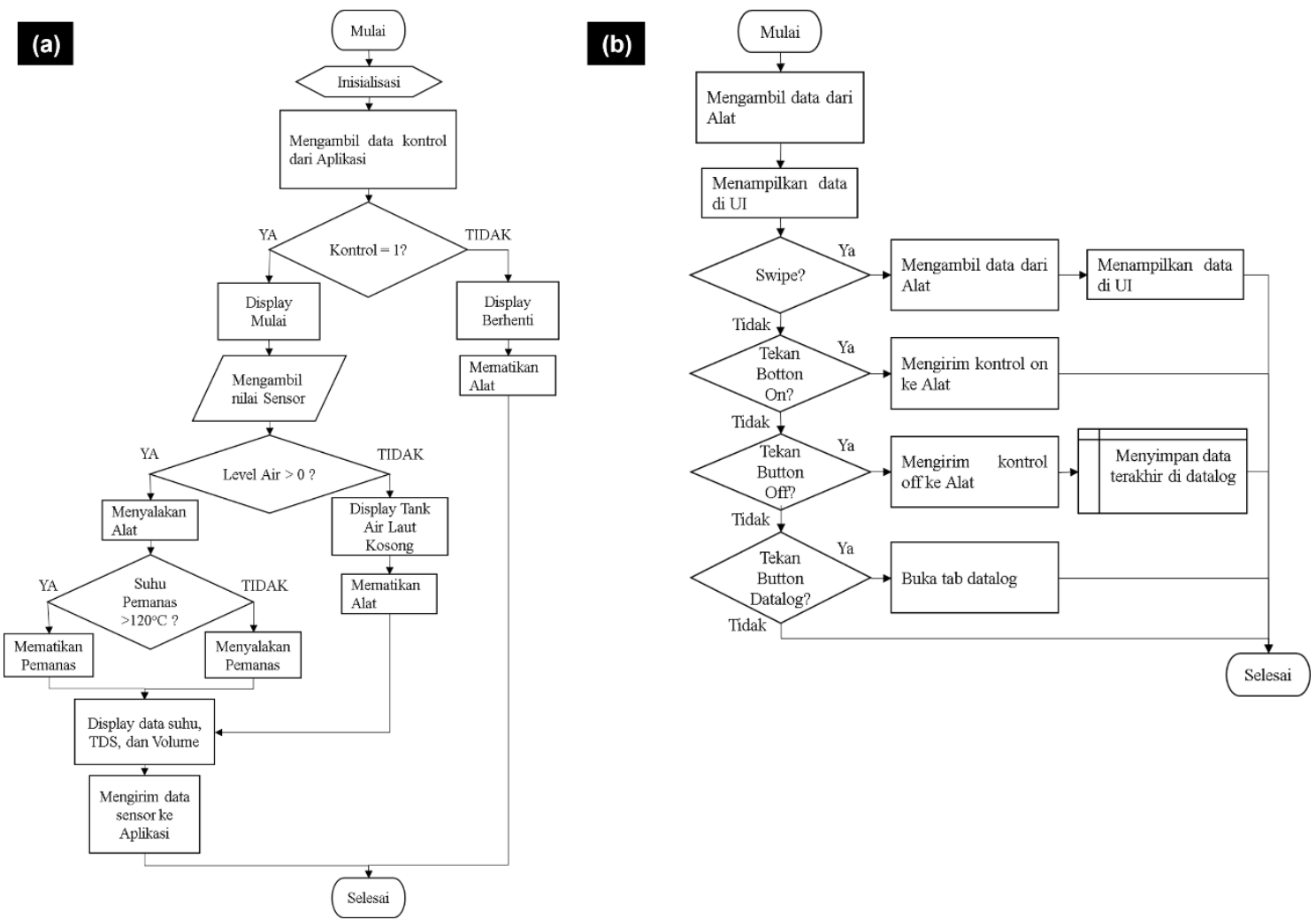

Gambar 3. Flowchart: (a) Alat dan (b) Aplikasi

\section{IMPLEMENTASI MODEL DAN PEMBAHASAN}

\section{A. Pengujian Sensor}

\section{Sensor Ultrasonik}

Pengujian dilakukan dengan membandingkan pembacaan besaran "jarak" dari sensor dan menggunakan penggaris. Sensor menggunakan bidang pantul air dan pengujiannya dilakukan pada jarak 3-17 cm. Hasil pengujian tersebut ditunjukkan pada Tabel II. Dapat dilihat untuk jarak $1 \mathrm{~cm}$ dan $2 \mathrm{~cm}$, pembacaan jarak yang didapatkan sangat tidak stabil karena posisi bidang pantul 
yang terlalu dekat dengan sensor (terjadi pembacaan pemantulan berulang yang sangat cepat). Untuk jarak $3 \mathrm{~cm}$ hingga $30 \mathrm{~cm}$, sensor memiliki error 1,34\% dan akurasi sebesar 98,66\%. Jarak tersebut selanjutnya dikonversi menjadi volume (khususnya volume tabung), untuk keperluan menghitung volume air tawar yang dihasilkan, mengikuti persamaan (1), dengan $r$ sebagai jarijari dan $t$ sebagai tinggi tabung.

$$
\text { Volume }=\pi r^{2} t
$$

TABEL II

HASIL PENGUJIAN SENSOR ULTRASONIK

\begin{tabular}{|c|c|c|c|c|c|c|c|c|c|}
\hline \multirow[b]{2}{*}{ No } & \multicolumn{2}{|c|}{ Jarak $(\mathrm{cm})$} & \multirow[b]{2}{*}{ Selisih } & \multirow{2}{*}{$\begin{array}{l}\text { Eror } \\
(\%)\end{array}$} & \multirow[b]{2}{*}{ No } & \multicolumn{2}{|c|}{ Jarak $(\mathrm{cm})$} & \multirow[b]{2}{*}{ Selisih } & \multirow{2}{*}{$\begin{array}{l}\text { Eror } \\
(\%)\end{array}$} \\
\hline & $\begin{array}{c}\text { Penggari } \\
\mathrm{s}\end{array}$ & $\begin{array}{c}\text { Senso } \\
\mathrm{r}\end{array}$ & & & & $\begin{array}{c}\text { Penggari } \\
\mathrm{s}\end{array}$ & $\begin{array}{c}\text { Senso } \\
\mathrm{r}\end{array}$ & & \\
\hline 1 & 3 & 2,90 & 0,10 & 3,33 & 16 & 18 & 17,84 & 0,16 & 0,89 \\
\hline 2 & 4 & 3,96 & 0,04 & 1,00 & 17 & 19 & 18,55 & 0,45 & 2,37 \\
\hline 3 & 5 & 4,83 & 0,17 & 3,40 & 18 & 20 & 19,88 & 0,12 & 0,60 \\
\hline 4 & 6 & 5,81 & 0,19 & 3,17 & 19 & 21 & 20,68 & 0,32 & 1,52 \\
\hline 5 & 7 & 6,75 & 0,25 & 3,57 & 20 & 22 & 21,26 & 0,74 & 3,36 \\
\hline 6 & 8 & 7,73 & 0,27 & 3,37 & 21 & 23 & 22,67 & 0,33 & 1,43 \\
\hline 7 & 9 & 8,60 & 0,40 & 4,44 & 22 & 24 & 23,64 & 0,36 & 1,50 \\
\hline 8 & 10 & 9,62 & 0,38 & 3,80 & 23 & 25 & 24,85 & 0,15 & 0,60 \\
\hline 9 & 11 & 10,61 & 0,39 & 3,55 & 24 & 26 & 25,47 & 0,53 & 2,04 \\
\hline 10 & 12 & 11,58 & 0,42 & 3,50 & 25 & 27 & 26,48 & 0,52 & 1,93 \\
\hline 11 & 13 & 12,45 & 0,55 & 4,23 & 26 & 28 & 27,41 & 0,59 & 2,11 \\
\hline 12 & 14 & 13,44 & 0,56 & 4,00 & 27 & 29 & 28,62 & 0,38 & 1,31 \\
\hline 13 & 15 & 14,73 & 0,27 & 1,80 & 28 & 30 & 29,56 & 0,44 & 1,47 \\
\hline 14 & 16 & 15,45 & 0,55 & 3,44 & & Rata-rata & & 0,35 & 2,46 \\
\hline 15 & 17 & 16,79 & 0,21 & 1,24 & & & & & \\
\hline
\end{tabular}

\section{Sensor TDS}

TABEL III

HASIL PENGUJIAN SENSOR TDS

\begin{tabular}{|c|c|c|c|}
\hline \multirow[b]{2}{*}{$\mathrm{NO}$} & \multicolumn{2}{|c|}{ Salinitas (ppm) } & \multirow[b]{2}{*}{$\begin{array}{l}\text { Eror } \\
(\%)\end{array}$} \\
\hline & $\begin{array}{c}\text { Larutan } \\
\text { Kalibrasi }\end{array}$ & $\begin{array}{c}\text { Sensor } \\
\text { TDS }\end{array}$ & \\
\hline 1 & 100 & 107,23 & 4,5 \\
\hline 2 & 200 & 202,3 & 1,15 \\
\hline 3 & 300 & 303,13 & 1,04 \\
\hline 4 & 400 & 401,26 & 0,31 \\
\hline 5 & 500 & 509,76 & 1,95 \\
\hline 6 & 600 & 609,36 & 1,56 \\
\hline 7 & 700 & 710,66 & 1,52 \\
\hline 8 & 800 & 811,4 & 1,43 \\
\hline 9 & 900 & 909,5 & 1,05 \\
\hline 10 & 1000 & 1044,5 & 4,45 \\
\hline \multicolumn{3}{|c|}{ Rata-rata } & 1,9 \\
\hline
\end{tabular}

Pengujian sensor TDS dilakukan dengan membandingkan pembacaan sensor dengan larutan garam dengan berbagai konsentrasi berbeda (100-1000 ppm), dengan pelarut air dan zat 
terlarutnya garam. Tabel III menunjukkan angka rata-rata hasil pengujian pada setiap larutan kalibrasi, dimana hasil pengujian menunjukkan bahwa error sensor adalah $\pm 1,90 \%$ dan akurasi sebesar $98,10 \%$.

$$
V_{1} \times C_{1}=V_{2} \times C_{2}
$$

Dengan

$V_{l}=$ Volume larutan yang dibuat $(\mathrm{ml})$

$V_{2}=$ Volume larutan awal $(\mathrm{ml})$

$C_{l}=$ Kadar salinitas yang ingin dibuat $(\mathrm{mg} / \mathrm{L})$

$C_{2}=$ Kadar salinitas induk $(\mathrm{mg} / \mathrm{L})$

\section{Sensor Suhu}

Pengujian sensor suhu dilakukan dengan membandingkan pembacaan suhu pada sensor dengan termometer D24. Tabel IV menunjukkan hasil rata-rata pembacaan suhu sensor terhadap suhu yang telah ditentukan dengan error untuk sensor 1 sebesar $\pm 0,97 \%$, sensor 2 sebesar \pm $1,13 \%$, sensor 3 sebesar $\pm 1,10 \%$, dan sensor termokopel sebesar $\pm 0,24 \%$. Pembacaan sensor dipengaruhi oleh faktor lingkungan tempat pengujian dan batasan akurasi sensor yang digunakan.

TABEL IV

HASIL PENGUJIAN SENSOR SUHU

\begin{tabular}{|c|c|c|c|c|}
\hline \hline Suhu $\left({ }^{\circ} \mathrm{C}\right)$ & $\begin{array}{c}\text { Sensor } \\
1\end{array}$ & $\begin{array}{c}\text { Sensor } \\
2\end{array}$ & $\begin{array}{c}\text { Sensor } \\
3\end{array}$ & $\begin{array}{c}\text { Sensor } \\
4\end{array}$ \\
\hline 50 & 49,64 & 49,75 & 49,44 & 50,16 \\
\hline 60 & 59,35 & 59,21 & 59,2 & 59,98 \\
\hline 70 & 69,24 & 69,21 & 69,13 & 70,28 \\
\hline 80 & 79,34 & 79,04 & 79,37 & 80,26 \\
\hline 90 & 89,28 & 89 & 89,28 & 90,5 \\
\hline 100 & 98,69 & 98,5 & 98,66 & 99,86 \\
\hline Eror (\%) & 0,97 & 1,13 & 1,1 & 0,24 \\
\hline
\end{tabular}

4. Sensor Ketinggian Air

Pengujian sensor ketinggian air dilakukan dengan memasukkan probe water level pada kapasitas volume yang telah ditentukan. Gambar 4 menunjukkan pembacaan rentang nilai ADC pada setiap kapasitas volume (dalam satuan \%), sehingga dengan mengelompokkan rentang nilai ADC yang didapat berdasarkan kapasitasnya, sensor dapat digunakan untuk mengukur kapasitas air di dalam pemanas.

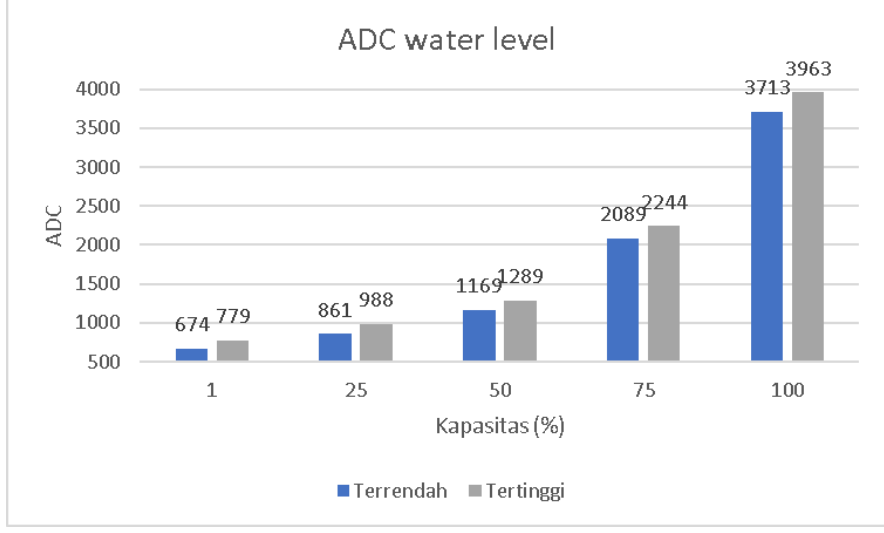

Gambar 4. Range ADC Sensor Ketinggian Air 


\section{B. Pengujian Alat Desalinasi Air Laut}

Gambar 5 menunjukkan hasil perancangan sistem desalinasi air laut. Secara umum, prosesnya adalah sebagai berikut: Pertama, air garam/air laut yang akan dikonversi menjadi air tawar dimasukkan ke dalam tempat penampungan. Selanjutnya, akan terjadi proses pemanasan kepada air tersebut, dimana suhunya akan di-set sekitar $100^{\circ} \mathrm{C}$, sehingga air akan menguap dan garam akan mengkristal padat. Hasil uap tersebut adalah perubahan fasa air menjadi gas. Selanjutnya, uap air yang dihasilkan akan didinginkan, supaya fasa gas menjadi cair kembali. Hasil pendinginan ini selanjutnya akan menyebabkan hasil air tawar.

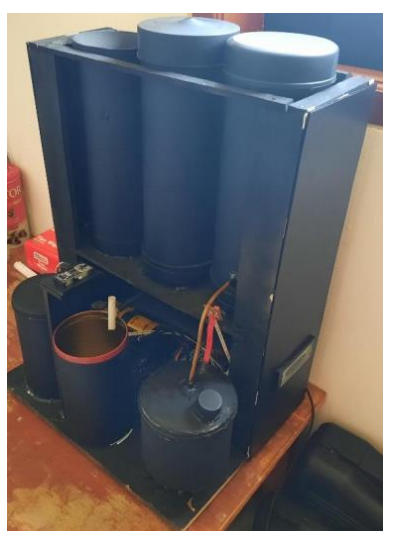

Gambar 5. Hasil Alat Desalinasi Air Laut

Terkait pengujian sistem, pengujian konversi air garam/air laut menjadi air tawar dilakukan dengan menguji alat yang telah dirancang dan memvariasikan volume air dan konsentrasi garam yang berbeda. Pengujian dilakukan dengan 4 skenario, yaitu:

1. $V_{\text {air }}=500 \mathrm{ml}, C=1000 \mathrm{ppm}$ (diuji sebanyak 10x)

2. $V_{\text {air }}=500 \mathrm{ml}, C=2000 \mathrm{ppm}$ (diuji sebanyak $10 \mathrm{x}$ )

3. $V_{\text {air }}=500 \mathrm{ml}, C=3000 \mathrm{ppm}$ (diuji sebanyak 10x)

4. $V_{\text {air }}=500 \mathrm{ml}$ air laut diuji sebanyak $10 \mathrm{x}$

Hasil pengujian proses desalinasi dengan keempat skenario di atas ditunjukkan pada Tabel V. Pada dasarnya, waktu yang dibutuhkan untuk melakukan 1 kali proses desalinasi adalah sekitar 3 jam, dan pengujian telah dilakukan sebanyak 40 kali. Hasil pengukuran kadar salinitas air setelah proses menunjukkan bahwa semua air sekarang telah memiliki kadar salinitas < $100 \mathrm{mg} / \mathrm{L}$ (tergolong air tawar). Hasil perbandingan antara air tawar terhadap air garam awal pun menunjukkan air tawar yang didapat $>90 \%$, untuk semua pengujian. Hasil ini menunjukkan bahwa sistem dapat bekerja dengan baik dalam mengubah air garam menjadi air tawar.

TABEL $\mathrm{V}$

HASIL PENGUJIAN ALAT DESALINASI

\begin{tabular}{|c|c|c|c|c|}
\hline \multirow[b]{2}{*}{ Skenario } & \multirow{2}{*}{$\begin{array}{c}\text { Durasi } \\
\text { (jam) }\end{array}$} & \multicolumn{2}{|c|}{ Air Hasil Desalinasi } & \multirow{2}{*}{$\begin{array}{c}\text { Volume Air } \\
\text { Setelah } \\
\text { Desalinasi } \\
(\%)\end{array}$} \\
\hline & & $\begin{array}{l}\text { Volume } \\
\text { (ml) }\end{array}$ & $\begin{array}{c}\text { Salinitas } \\
(\mathrm{ppm})\end{array}$ & \\
\hline 1 & $02: 59$ & 459,22 & 5,9 & 91,84 \\
\hline 2 & $02: 59$ & 470,81 & 0 & 94,16 \\
\hline 3 & 03:00 & 464,88 & 0 & 92,98 \\
\hline 4 & 03:04 & 459,96 & 0 & 91,99 \\
\hline Rata-rata & 03:01 & 463,72 & 1,48 & 92,74 \\
\hline
\end{tabular}

Prosiding Seminar Nasional Sains Teknologi dan Inovasi Indonesia - Akademi Angkatan Udara Volume 3, Tahun 2021: hlm. 169-178 


\section{Hasil Mobile Application}

Gambar 6 adalah hasil display mobile application yang telah dirancang. Fitur-fiturnya antara lain adalah menu utama, tombol ON/OFF untuk menyalakan dan mematikan alat, fitur-fitur data monitoring (data suhu, salinitas, volume), dan juga fitur datalog untuk masuk ke layar datalog dan menampilkan data tersimpan. Terkait hasil tampilan mobile application ini, pengujian delay pengiriman pun dilakukan.

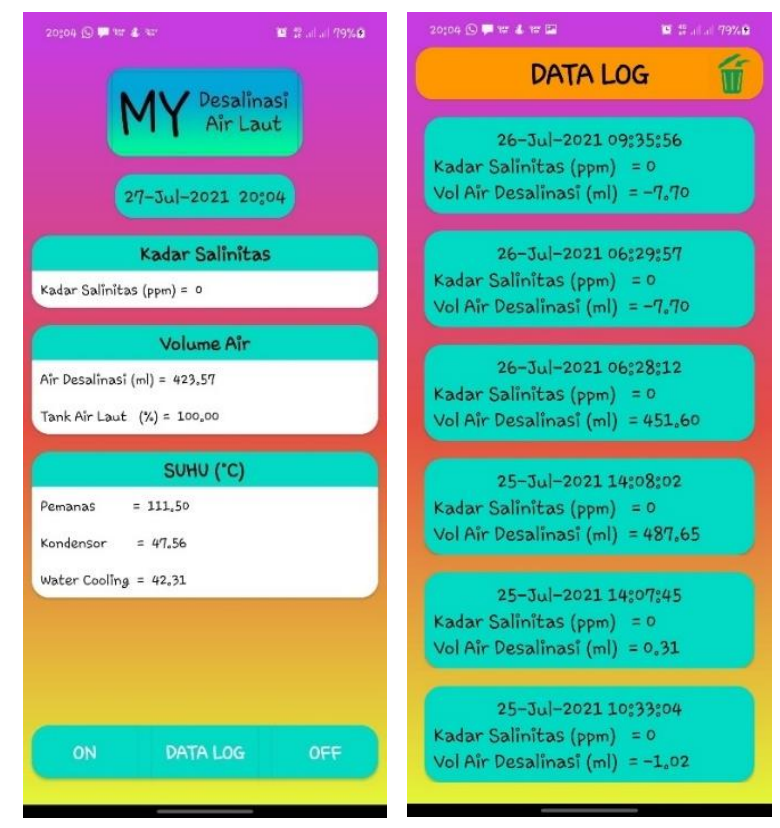

Gambar 6. Tampilan Mobile Application

Gambar 7(a) menunjukkan pengujian data waktu tempuh ketika mengirimkan dan menerima data dari ESP32 ke Antares selama 30 kali berturut-turut. Rata-rata waktu tempuh total pengiriman data dari ESP32 ke Antares adalah 1,364 detik. Gambar 7(b) menunjukkan data waktu tempuh ketika mengirimkan dan menerima data dari aplikasi Android ke Antares. Rata-rata waktu yang dibutuhkan adalah 1,819 detik. Waktu kirim data antara ESP32 dengan aplikasi Android melalui Platform Antares dipengaruhi oleh kecepatan internet dan jangkauan jaringan yang digunakan.

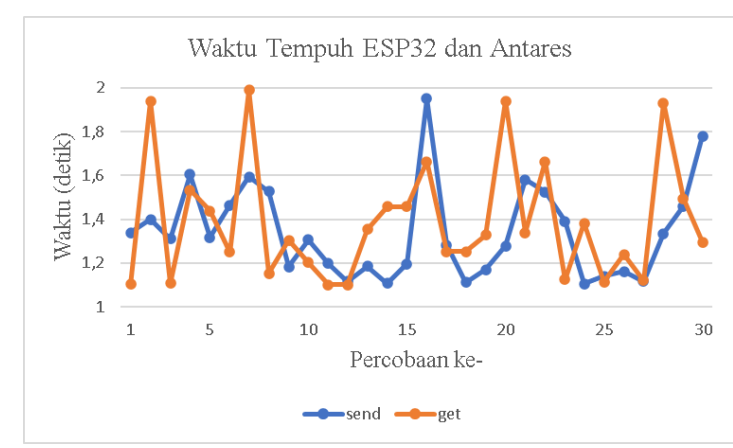

(a)

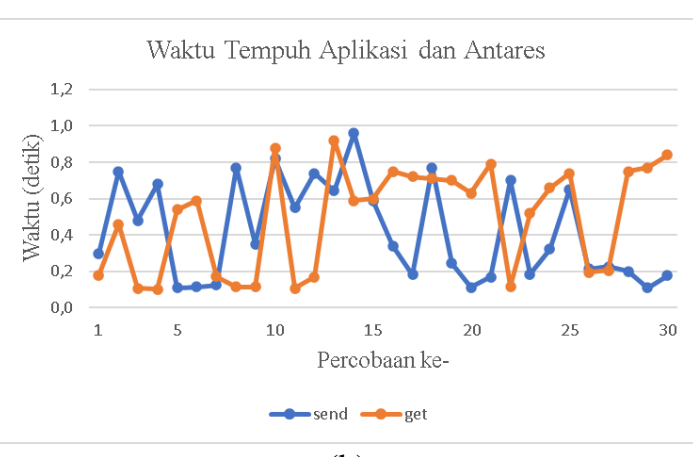

(b)

Gambar 7. (a) Waktu Tempuh ESP32 ke Antares dan (b) Waktu Tempuh Aplikasi ke Antares 


\section{KESIMPULAN}

Sistem otomatisasi desalinasi air laut menggunakan metode desalinasi termal telah dirancang dengan memanfaatkan kontrol dan monitoring melalui platform IoT Antares. Hasil pengujian desalinasi menunjukkan bahwa rata-rata hasil air desalinasi 92,74\% (yang menjadi air tawar), dengan kadar salinitas 1,47 ppm. Rata-rata waktu yang dibutuhkan untuk mengubah air garam untuk menjadi air tawar adalah 3 jam. Selain itu, pengujian dapat dikontrol dan dipantau dengan aplikasi android dengan rata-rata waktu tempuh data adalah 1,819 detik. Untuk ke depannya, sistem aplikasi ini perlu ditingkatkan dalam hal pengujian sebenarnya menggunakan air laut dan juga dari sisi bahan agar tahan terhadap korosi karena air laut.

\section{REFERENSI}

[1] I. Kusumawati, "Analisis Kebutuhan Air Bersih Di Kecamatan Selat Nasik Kabupaten Belitung Provinsi Bangka Belitung Tahun 2017," J. Environ. Eng. Waste Manag., vol. 3, no. 1, pp. 30-35, 2018, doi: 10.33021/jenv.v3i1.399.

[2] E. Noviyanti and R. P. Setiawan, "Penyediaan Air Bersih pada Kawasan Rawan Air Bersih di Pesisir Utara Lamongan," J. Tataloka, vol. 16, no. 2, p. 116, 2014, doi: 10.14710/tataloka.16.2.116132.

[3] A. Gurib-Fakim et al., "Making Every Drop Count-An Agenda for Water Action," HLPWater Outcome Rep., no. March, p. 234, 2018, doi: 10.3362/0262-8104.1993.008.

[4] I. Nurjannah and Sudarsono, "Penerapan Destilator Air Laut Sebagai Solusi Ketiadaan Sumber Air bagi Suku Bajo di Kabupaten Wakatobi,” Semin. Nas. Teknol. Terap. Berbas. Kearifan Lokal, 2018.

[5] Z. Wang et al., "Nanoparticle-templated nanofiltration membranes for ultrahigh performance desalination," Nat. Commun., vol. 9, no. 1, 2018, doi: 10.1038/s41467-018-04467-3.

[6] J. Tonner, "Barriers to Thermal Desalination in the United States," 2008.

[7] N. T. Wahyudi, F. F. Ilham, I. Kurniawan, and A. S. Sanjaya, "Rancangan Alat Distilasi untuk Menghasilkan Kondensat dengan Metode Distilasi Satu Tingkat," J. Chemurg., vol. 1, no. 2, p. 30, 2018, doi: $10.30872 / \mathrm{cmg} . v 1 i 2.1142$.

[8] U. P. Astuti, "Atap Desalinasi Sebagai Solusi Pemenuhan Kebutuhan Air Bersih Di Daerah Pesisir," J. Res. Technol., vol. 2, no. 2, 2016, doi: 10.5281/zenodo.2581992.

[9] I. G. Y. Dewantara, B. M. Suyitno, and I. G. E. Lesmana, "Desalinasi Air Laut Berbasis Energi Surya Sebagai Alternatif Penyediaan Air Bersih,"J. Tek. Mesin, vol. 7, no. 1, p. 1, 2018, doi: 10.22441/jtm.v7i1.2124.

[10] M. A. Azis and N. Fajaryati, "Reosquido Desalinasi Metode Evaporasi dengan Ultraviolet Berbasis Mikrokontroller," Elinvo (Electronics, Informatics, Vocat. Educ., vol. 3, no. 2, pp. 38-47, 2018, doi: 10.21831/elinvo.v3i2.20885.

[11] A. Sujiwa and Atmiasri, "Sistem Kontrol Efisiensi Daya Otomatis Pada Perangkat Prototipe Desalinasi Dual Output Bertenaga Sel Surya," Tek. Waktu, vol. 17, p. 26, 2019.

[12] A. Sujiwa and S. Rochman, "Pengembangan Sistem Kontrol Serta Monitoring Suhu dan Volume Air Berbasis Web Pada Perangkat Desalinasi Air Laut," Semin. Nas. Has. Ris. dan Pengabdi., vol. II, pp. 1-9, 2019.

[13] D. Arief, "Pengukuran Salinitas Air Laut Dan Peranannya Dalam Ilmu Kelautan," Oseana, vol. IX, no. 1 , pp. 3-10, 1984.

[14] L. Rose, G. R. D. Selvaeva, and X. A. Mary, "TDS Measurement Using Machine Learning Algorithm,” 2018 Int. Conf. Circuits Syst. Digit. Enterp. Technol. ICCSDET 2018, pp. 2018-2021, 2018, doi: 10.1109/ICCSDET.2018.8821101.

[15] J. K. Fawell et al., "Total Dissolved Solids in Water," Guidel. Drink. Qual., vol. 2, no. Health criteria and other supporting information, 1996. 